\title{
Pharmacological Treatment for Pregnant Women who Smoke Cigarettes
}

\author{
Chan BC, Koren G \\ The Motherisk Program, Division of Clinical Pharmacology and Toxicology, \\ The Hospital for Sick Children, University of Toronto, Toronto, Ontario, Canada
}

\begin{abstract}
Smoking has been associated with several concerns in pregnancy including miscarriage, preterm delivery and stillbirth. Unfortunately, approximately $12 \%$ of the pregnant population continue to smoke cigarettes, suggesting a need for additional therapy beyond behavioural change. This paper reviews the literature on the use of nicotine replacement therapy and bupropion $\left(\mathrm{Zyban}^{\circledR}\right)$ in the pregnant human population, the pharmacokinetics of nicotine in the pregnant woman, and current guidelines for smoking cessation for pregnant patients. There are currently four studies that have investigated the use of nicotine patch, three for nicotine gum, and registry and preliminary reports for bupropion. These studies did not show any adverse pregnancy outcomes with the use of pharmacological aid for smoking cessation. All the nicotine replacement therapy studies, with the exception of one randomized-controlled nicotine patch trial had small sample sizes and looked at shortterm use of drug in the third trimester. Two studies have examined the pharmacokinetics of nicotine in the pregnant woman. The results from these studies reveal greater nicotine metabolism in pregnant individuals who continue to smoke during pregnancy. Current guidelines from several organizations uniformly recommend that Nicotine Replacement Therapy should be considered if non-pharmacological therapies have been unsuccessful. Bupropion is recommended in pregnancy if the benefits outweigh the risks. There is a need for further studies on the safety and effectiveness of Nicotine Replacement therapy and bupropion in pregnancy. However, considering the current research and guidelines, pharmacological cessation aids should be considered if non-pharmacological therapies have not been effective.
\end{abstract}

\section{INTRODUCTION}

Smoking during pregnancy is a serious teratogenic concern. As early as the 1960 s, research revealed a relationship between smoking and birth-weight [1]. Since then, numerous studies have found an association between smoking and an increased risk of several other adverse effects in pregnancy (Table 1). From this information, the general population has been well informed that smoking during pregnancy is a risky behaviour. In a 1999 Annenberg Tobacco Survey given to 14- to 22year-olds in the US, $97 \%$ of non-smokers and $93 \%$ of smokers identified that smoking while pregnant can harm the baby [2]. This risk was more widely identified in the survey than deaths due to second-hand smoke and smoking causing lung damage after a few years. Despite the risk of smoking in pregnancy being well established in society, many pregnant women continue to smoke. The National Vital Statistics Report in the US reported that 12.2 percent of all women giving birth in 2000 reported smoking during pregnancy [3]. With 4 million births in the US for the same year, approximately 500,000 pregnancies were at risk because of maternal smoking. In the non-pregnant population, smoking cessation using nicotine replacement therapy (NRT), in the form of gum, patch, lozenge, nasal spray and inhaler have been found to be efficacious in increasing quit rates [4-19]. As a result, NRT has been an

Correspondence: Gideon Koren, MD, Director, The Motherisk Program, Division of Clinical Pharmacology and Toxicology, The Hospital for Sick Children, University of Toronto, Toronto, Ontario, M5G 1X8, Canada Email: gkoren@sickkids.ca Fax: +416-813-7562 
acceptable aid for smoking cessation in the general population.

The drug manufacturers, on the other hand, have contraindicated the use of NRT in the pregnant population. In a survey of six Boston, Massachusetts, obstetric clinics from 1996-1997, 42\% of the obstetric providers did not discuss nicotine replacement therapy with any of their patients who continued to smoke cigarettes [20]. Given a hypothetical scenario about a 20-cigarettes-perday smoking pregnant woman motivated to quit using nicotine replacement therapy, $44 \%$ of the obstetric providers considered it usual practice to prescribe or recommend NRT [20]. However, if the safety of nicotine replacement therapy use in pregnancy was supported by "definitive evidence," the number of practitioners recommending or prescribing this therapy increased to $92 \%$. This stresses the importance of understanding the safety and effectiveness of NRT use in pregnancy. Currently several studies have looked at the use of nicotine patch and nicotine gum in pregnant individuals.

\section{NICOTINE REPLACEMENT THERAPIES AND PREGNANCY}

\section{Nicotine Patch}

Currently four studies have been conducted on the use of nicotine patch in pregnant women. A prospective study by Wright et al $(\mathrm{n}=6)$ [21], monitored the mother and fetus during and after a six-hour application of 21-mg transdermal nicotine patch, following a day of smoking abstinence. Another prospective controlled study by Ogburn et al $(\mathrm{n}=21)$ [22], assessed maternal and fetal effects during a four-day application of 22-mg transdermal patch. Baseline measurements in normal smoking conditions were conducted within a week of patch application. Both studies did not find significant changes in fetal heart rate and umbilical artery Doppler examination readings. The participants in both studies smoked between 10 to 50 cigarettes per day during their pregnancy. A more recent study also enrolled 21 pregnant women smoking more than 15 cigarettes per day [23]. Participants were given 22-mg nicotine patches (24 hours/day) and monitored for four days in-hospital followed by an eight-week period outside the hospital setting. In all patients, non-stress tests were reactive or became reassuring with observation. There were also no significant pre-term deliveries in this study (gestational age ranged between 36.3 to 41.1 weeks). In all three studies, participants were enrolled in the third trimester, so results are limited to the later part of pregnancy. The forth, and only randomized controlled study investigat-
Table 1: Reproductive concerns that are associated with cigarette smoke exposure

Ectopic Pregnancy 40-47

Premature Rupture of Membrane 46;48-53

Abruptio Placentae 46;54-63

Spontaneous Abortion 64-68

Placenta Previa 55;69-78

Low birthweight $(<2500 \mathrm{~g}) /$ Small for Gestational

Age 79-105

Preterm Delivery (<37 weeks) 106-111

Stillbirth 112-115

Neonatal mortality $116 ; 117$

Perinatal mortality 105

SIDS 118;119

Cognitive deficit 120-122

ing nicotine patch and pregnancy $(\mathrm{n}=250)$ was published by Wisborg et al [24]. Healthy pregnant women less than 22 weeks pregnant, smoking more than 10 cigarettes per day were given prenatal smoking cessation counseling by a midwife four times during the pregnancy and assigned either nicotine patch or placebo. Treatment duration was 11 weeks for both groups. In the active group, participants were given 15-mg patches (16 hours/day) for eight weeks followed by 10 mg patches (16 hours/day) for three weeks. In this Danish study, the mean birth weight of the newborns was $186 \mathrm{~g}(95 \% \mathrm{CI})$ heavier than the control group. The investigators also found no significance in the rate of low birth weight (less than $2500 \mathrm{~g}$ ) and preterm babies between groups. Of the participants in the nicotine patch group, $26 \%$ had stopped smoking throughout the pregnancy and $14 \%$ remained smoked free at one-year postpartum. Both these results were not significant to the control group.

Another controlled study has also looked at the efficacy of nicotine patch in pregnant women [25]. Kapur et al recruited pregnant women in their second trimester and smoking more than 15 cigarettes per day. Participants were randomized to receive either nicotine transdermal patch or placebo patch for 12 weeks. The active group received $15-\mathrm{mg}$ patches (18 hours/day) for eight weeks, followed by $10-\mathrm{mg}$ patches (18 hours/day) for two weeks, then 5-mg (18 hours/day) for two 
weeks. Researchers enrolled 30 patients before ending the study prematurely after one patient experienced severe signs of withdrawal and rapid and forceful movements from the fetus. These symptoms subsided after the patient smoked a cigarette. Fetal ultrasound, an obstetrical examination and a nonstress test were normal. Of the individuals participating in the study, 17 received nicotine patch, 13 received placebo. Success rates between active and controller rates were not statistically significant, with only three participants completing their assigned therapy in the active group and no participants in the control group.

\section{Nicotine Gum}

Several studies have looked at the use of nicotine gum in pregnant smokers. Specifically, these studies measured maternal nicotine levels and short-term fetal response to nicotine gum. One of the earliest studies in nicotine and fetal response [26] measured fetal breathing movements in 12 pregnant women before and after chewing nicotine gum $\left(\right.$ Nicorette $\left.^{\circledR}\right)$. Seven participants received one piece of gum containing $4 \mathrm{mg}$ nicotine, while the other five were given two pieces to take simultaneously. Nicotine levels were obtained from venous blood taken before nicotine gum administration, 30 minutes and 60 minutes after the initiation of chewing. There was a significant decrease in fetal breathing 25 minutes after administration of $8 \mathrm{mg}$ nicotine gum, but slowly recovered to non-significant levels at 35 minutes after administration. Decreased fetal breathing was not significant for participants taking the $4 \mathrm{mg}$ nicotine gum. In a separate study [27] $(\mathrm{n}=12)$, investigators compared maternal and fetal response when participants used $4 \mathrm{mg}$ nicotine gum and when they used placebo gum. Participants were given a chewing gum combination of: one piece nicotine followed by one piece placebo, two nicotine gums one after the other, or two placebo gums. Each participant was given all three combinations on separate days. Maternal heart rate, diastolic and systolic blood pressures increase after nicotine gum use but not placebo gum use. Also, fetal heart rate, aortic blood flow and umbilical venous blood flow were unchanged with nicotine and placebo gum use. A more recent study compared nicotine gum to cigarette smoking in separate groups of pregnant women. For a five-day period, 19 participants received nicotine gum, while 10 continued to smoke. Individuals in the nicotine gum group were given a fixed dosage regimen of at least six pieces of gum a day but no more than 30 pieces per day or two pieces per hour. This study found no difference in maternal heart rate and blood pressure, fetal heart rate and umbilical artery resistance [28]. Lower maternal blood nicotine levels were observed in gum use versus smoking, suggesting that in pregnant women, nicotine gum delivers less nicotine than cigarette smoking. All three studies only enrolled pregnant women in their third trimester and smoking more than 10 cigarettes per day.

\section{NON-NICOTINE SMOKING CESSATION THERAPIES AND PREGNANCY}

\section{Bupropion}

Zyban (bupropion) is gaining popularity as an alternative to administering nicotine for smoking cessation. Originally intended to treat depression, one of the side effects of bupropion was smoking cessation. Currently, bupropion is classifed as Pregnancy Category B, indicating a negative association with fetal harm in animal studies, but no well-controlled studies in human pregnancies. Teratology tests by the manufacturer have been conducted up to doses of $450 \mathrm{mg} / \mathrm{kg}$ in rats and up to $150 \mathrm{mg} / \mathrm{kg}$ in rabbits, without impaired fertility or fetal harm. The manufacturer has also assembled a bupropion pregnancy registry to understand the safety of this drug during pregnancy [29]. The most recent interim report, issued in December 2002, covered results from September 1997 to August 2002. As of August 2002, the registry had 668 patients enrolled, with 334 pregnancy outcomes. From the 334 pregnancy outcomes, there were 289 live births, 32 spontaneous abortions, one fetal death and 11 therapeutic abortions. Seven birth defects were reported from the 289 live births and one was reported from the therapeutic abortions. The eight birth defects were specifically: one child with bilateral clubfeet, another child with abnormal aortic valve thickening with secondary mild aortic insufficiency, one with ventricular septal defect, one with trivial valvular pulmonic stenosis, one with Klinefelter's Syndrome but no physical abnormalities, one with congenital heart defect (coarctation) and ventricular septal defect, one premature infant with a thickened heart muscle and one induced abortion with possible Down Syndrome detected in prenatal test. GlaxoSmithKlein also receive retrospective reports of pregnant women using bupropion and their outcomes. From these reports there have been 11 cases of birth defects. An Advisory Committee overseeing the bupropion registry did not find a common pattern among the prospective reports of birth defects. Of the nine retrospective cases, there were four cardiac-related defects. However, whether the rate of cardiac defects is significantly high- 
er than the general population remains undetermined because the denominator is unknown, and because of the bias found in retrospective reports. Motherisk has an unpublished prospective, on-going study investigating the safety of bupropion use during pregnancy. Currently, there are 101 participants in the study and 97 pregnancy outcomes thus far. Of the pregnancy outcomes, there were 71 live births, 18 miscarriages and eight therapeutic abortions. There are still three pregnancies pending and one participant was lost to followup. Of the live births, there were no reports of major malformations. Miscarriage rate, mean birth weight and gestational age at delivery were all found to be nonsignificant when compared to a control group that consisted of pregnant women who had contacted Motherisk, but were not exposed to any teratogens.

\section{THE PHARMACOKINETICS OF NICOTINE DURING PREGNANCY}

There are two studies that have looked at the pharmacokinetics of nicotine in pregnant women. In a study by Selby et al, 19 Caucasian pregnant women had blood nicotine and cotinine levels measured [30]. This study group reported an inability to stop smoking during their pregnancy, despite understanding the risks. Levels of blood nicotine were lower than expected for the amount of cigarettes reportedly smoked. Cotinine levels, on the other hand, were higher than the average levels per cigarette in pregnant women. The results suggest an increase in nicotine metabolism in a subgroup of pregnant women who cannot stop smoking. A separate study by Dempsey et al measured levels of nicotine and cotinine in 10 pregnant women after infusion of deuterium labelled nicotine [31]. Women were given one or two 30-minute infusions during pregnancy and one infusion post-partum. The dose of nicotine given (1.0 or $1.5 \mathrm{micrograms} / \mathrm{kg} / \mathrm{min}$ ) was similar to smoking two cigarettes. A comparison of nicotine and cotinine levels during and post pregnancy revealed significant increases in nicotine and cotinine clearance during pregnancy. The authors concluded that all pregnant women have accelerated nicotine metabolism. However, in this study, all participants were active smokers during their pregnancy. The results from this study may not represent the metabolism levels of environmental nicotine in non-smokers and ex-smokers. Further studies are necessary to accurately determine whether an increase in nicotine metabolism is found in all pregnant women or only in pregnant women who can't stop smoking. These two studies were also unable to determine whether the observed increase in metabolism is a result of a larger number of metabolism enzyme CYP3s, or greater hepatic clearance due to the pregnancy. There are still many questions surrounding the pharmacokinetics of nicotine during pregnancy. A better understanding of this area will help health authorities set up proper guidelines for smoking cessation in pregnancy.

\section{CURRENT GUIDELINES FOR SMOKING CESSATION IN PREGNANCY}

\section{Nicotine Replacement Therapy}

In the 2002 edition of the CPS all brands of nicotine gum and patch are contraindicated during pregnancy. The monograph for $\mathrm{Nicotrol}^{\circledR}$, available only in the US, elaborated on the reasoning behind the contraindication, stating tobacco smoke and nicotine through animal studies have been shown to cause fetal harm. Therefore the use of this nicotine product may also cause damage to the human fetus.

Most guidelines on the use of NRT and pregnancy, however, do not agree with such restrictions. The Ontario Medical Association (OMA) in literature published in 1999 have recommended that "NRT should be made available to pregnant women who are unable to quit using non-pharmacological methods [32]. Physicians should closely monitor nicotine dosage to ensure that nicotine levels do not exceed smoking levels. As with other drugs, NRT dosage should be matched to suit the smoker's needs." It was also recommended that "Health Canada's labelling requirements should be modified to include consideration of NRT use among pregnant women." The American Agency for Health Care Policy and Research (AHCPR) has similar recommendations for its clinical practice guideline [33]. It is recommended that due to the risks of smoking to the fetus, pregnant smokers should be given more rigorous psychosocial interventions (e.g. videos, quit packages) that go beyond typical advice to quit. Such smoking cessation interventions should persist throughout the pregnancy to ensure abstinence. However if psychosocial intervention is not successful, pharmacotherapy is recommended as a consideration if the benefits of its use surpass the risks of the treatment and continued smoking. The Royal College of Physicians has also expressed similar recommendations for NRT and pregnancy use in Britain [34]. Currently, both France and Germany permit the use of all forms of NRT under physician advice and supervision, provided non-pharmacological methods have been unsuccessful 
[35]. The United Kingdom has made similar recommendations for the nicotine gum, lozenge, patch and tablet. However, the nicotine spray and inhaler remain contraindicated in pregnancy [35]. In the publication titled Women and the Tobacco Epidemic: Challenges in the $21^{s t}$ Century by the World Health Organization, Richard Windsor also recommends the use of NRT if non-pharmacological methods are unsuccessful [36]. Furthermore, it is suggested that five questions be considered by the physician when making the recommendation of NRT to a pregnant patient:

1. Has the patient been provided "Best Practice" (e.g. videos, information packages) methods yet did not quit?

2. Has the patient reported smoking more than 10 cigarettes per day?

3. Does the patient smoke her first cigarette within the first 60 minutes of getting up?

4. Has the patient indicated that she want to quit?

5. Is the fetus's gestational age less than 20 weeks?

There has been a suggestion that the recommendation to initially treat pregnant smokers with psychosocial interventions before considering NRT may not be beneficial to all patients. McNeill et al, in a critique of current NRT practices, suggests that smoking cessation therapy in pregnant patients will have the greatest impact if a medical professional assessed the patient's situation, earlier on in pregnancy, based on past quit attempts and smoking history [37]. A pregnant woman with a low probability of quitting smoking by nonpharmacological means should not be subjected to psychosocial interventions because of the risk of a failed quit attempt causing decreased motivation to stop and resulting in continual smoking during pregnancy. Therefore, the authors suggest the contraindication of NRT use in pregnancy be removed and medical professionals conduct an early assessment, suggesting NRTs to the pregnant mother if the probability of cessation without it is minimal.

\section{Bupropion}

The monograph for Zyban and Wellbutrin, mention animal studies showing no association between the use of bupropion and fetal harm. However, since animal studies do not necessarily reflect human outcomes and because there is a lack of controlled studies, according to the manufacturer, bupropion should be given to a pregnant woman only if it is necessary.

\section{CONCLUSION}

There have been several studies published about the use of different pharmacological treatments in pregnant women. Currently, none of these studies have revealed a serious concern with NRT or bupropion use during pregnancy. However, most of these studies have small patient numbers, focus on immediate effects of short term NRT use and are limited to use in the third trimester. Nicotine is associated with possible harm to the fetus so psychosocial/behavioural therapy is ideal. However, if non-pharmacological treatments are ineffective, pregnant patients with the physician's assistance should weigh the pros and cons of NRT use. On the one hand, NRTs contains only nicotine, eliminating the patient's exposure to carbon monoxide and other carcinogens. As well, the plasma nicotine levels obtained from NRT use is within the therapeutic range in pregnant women [38], and all formulations should give a smaller dose of nicotine than smoking [39]. On the other hand, the effectiveness of NRTs in pregnancy is still unknown and nicotine withdrawl may have serious consequences to the fetus. The risk to benefit ratio for NRT use in pregnancy is still inconclusive. However, NRT with close supervision by the physician can potentially satisfy a pregnant woman's desire to smoke without exposing the patient to nicotine levels higher than that obtained from smoking. Currently, research has not shown an association between bupropion use in pregnancy and fetal malformations. However, more research is required before any definite conclusions can be made. Physicians and patients should weigh the risks and benefits of taking this medication during pregnancy.

There is a need for further studies on the safety and effectiveness of NRT use in pregnancy. At the same time, greater effort should be placed in educating medical professionals about smoking cessation therapy for pregnant women, so health care providers can offer the best possible treatment. With better therapy in this specialized group, hundreds of pregnancies with adverse outcomes can be avoided.

\section{REFERENCES}

1. Frazer T, Davis G, Goldstein H, Goldstein I. Cigarette smoking and prematurity: A prospective study. Am.J.Obstet.Gynecol. 1961;81:988-96.

2. Jamieson P, Romer D. What do young people 
think they know about the risks of smoking? In Slovic P, ed., Smoking: risk, perception and policy, pp 51-63. Thousand Oaks: Sage Publications, 2001.

3. Martin J, Hamilton BE, Ventura SJ, Menacker F, Park MM. Births: Final Data for 2000. National Vital Statistics Reports 2002;50.

4. Fiore MC, Jorenby DE, Baker TB, Kenford SL. Tobacco dependence and the nicotine patch. Clinical guidelines for effective use. JAMA 1992;268: 2687-94.

5. Lam W, Sze PC, Sacks HS, Chalmers TC. Metaanalysis of randomised controlled trials of nicotine chewing-gum. Lancet 1987;2:27-30.

6. Shiffman S, Dresler CM, Hajek P, Gilburt SJ, Targett DA, Strahs KR. Efficacy of a nicotine lozenge for smoking cessation. Arch. Intern. Med 2002;162:1267-76.

7. Blondal T, Franzon M, Westin A. A double-blind randomized trial of nicotine nasal spray as an aid in smoking cessation. Eur. Respir. J 1997;10: 1585-90.

8. Schneider NG, Olmstead R, Mody FV, Doan K, Franzon M, Jarvik ME et al. Efficacy of a nicotine nasal spray in smoking cessation: a placebo- controlled, double-blind trial. Addiction 1995;90: 1671-82.

9. Hjalmarson A, Franzon M, Westin A, Wiklund O. Effect of nicotine nasal spray on smoking cessation. A randomized, placebo-controlled, doubleblind study. Arch. Intern. Med 1994;154:2567-72.

10. Silagy C, Mant D, Fowler G, Lodge M. Metaanalysis on efficacy of nicotine replacement therapies in smoking cessation. Lancet 1994;343:13942.

11. Bolliger CT, Zellweger JP, Danielsson T, van B, $\mathrm{X}$, Robidou A, Westin A et al. Smoking reduction with oral nicotine inhalers: double blind, randomised clinical trial of efficacy and safety. BMJ 2000;321:329-33.

12. Hjalmarson A, Nilsson F, Sjostrom L, Wiklund O. The nicotine inhaler in smoking cessation. Arch. Intern. Med 1997;157:1721-8.

13. Schneider NG, Olmstead R, Nilsson F, Mody FV, Franzon M, Doan K. Efficacy of a nicotine inhaler in smoking cessation: a double-blind, placebocontrolled trial. Addiction 1996;91:1293-306.

14. Shiffman S, Gorsline J, Gorodetzky CW. Efficacy of over-the-counter nicotine patch. Nicotine. Tob. Res. 2002;4:477-83.

15. Hays JT, Croghan IT, Schroeder DR, Offord KP,
Hurt RD, Wolter TD et al . Over-the-counter nicotine patch therapy for smoking cessation: results from randomized, double-blind, placebo-controlled, and open label trials. Am J Public Health 1999; 89:1701-7.

16. Davidson M, Epstein M, Burt R, Schaefer C, Whitworth G, McDonald A. Efficacy and safety of an over-the-counter transdermal nicotine patch as an aid for smoking cessation. Arch. Fam Med 1998;7:569-74.

17. Perng RP, Hsieh WC, Chen YM, Lu CC, Chiang SJ. Randomized, double-blind, placebo-controlled study of transdermal nicotine patch for smoking cessation. J Formos. Med Assoc. 1998;97:547-51.

18. Richmond RL, Harris K, de Almeida NA. The transdermal nicotine patch: results of a randomised placebo-controlled trial. Med J Aust. 1994; 161:130-5.

19. Cepeda-Benito A. Meta-analytical review of the efficacy of nicotine chewing gum in smoking treatment programs. J Consult Clin Psychol 1993; 61:822-30.

20. Oncken CA, Pbert L, Ockene JK, Zapka J, Stoddard A. Nicotine replacement prescription practices of obstetric and pediatric clinicians. Obstet. Gynecol. 2000;96:261-5.

21. Wright LN, Thorp JM, Jr., Kuller JA, Shrewsbury RP, Ananth C, Hartmann K. Transdermal nicotine replacement in pregnancy: maternal pharmacokinetics and fetal effects. Am J.Obstet.Gynecol. 1997;176:1090-4.

22. Ogburn PL, Jr., Hurt RD, Croghan IT, Schroeder DR , Ramin KD, Offord KP et al. Nicotine patch use in pregnant smokers: nicotine and cotinine levels and fetal effects. Am. J. Obstet. Gynecol. 1999;181:736-43.

23. Schroeder DR, Ogburn PL, Jr., Hurt RD, Croghan T, Ramin KD, Offord KP et al. Nicotine patch use in pregnant smokers: smoking abstinence and delivery outcomes. J.Matern.Fetal Med. 2002;11: 100-7.

24. Wisborg K, Henriksen TB, Jespersen LB, Secher NJ. Nicotine patches for pregnant smokers: a randomized controlled study. Obstet.Gynecol. 2000; 96:967-71.

25. Kapur B, Hackman R, Selby P, Klein J, Koren G. Randomized, Double-Blind, Placebo-Controlled Trial of Nicotine Replacement Therapy in Pregnancy. Curr.Ther.Res Clin Exp. 2001;62:274-8.

26. Manning FA,.Feyerabend C. Cigarette smoking and fetal breathing movements. Br. J. Obstet. Gy- 
naecol. 1976;83:262-70.

27. Lindblad A,.Marsal K. Influence of nicotine chewing gum on fetal blood flow. J. Perinat. Med. 1987;15:13-9.

28. Oncken CA, Hatsukami DK, Lupo VR, Lando HA, Gibeau LM, Hansen RJ. Effects of short-term use of nicotine gum in pregnant smokers. Clin. Pharmacol. Ther. 1996;59:654-61.

29. GlaxoSmithKlein. The bupropion pregnancy registry: interim report, 1 September 1997 through 31 August 2002. Issued: December 2002. Pharmaresearch Corp. Research Park, Wilmington, N.C.

30. Selby P, Hackman R, Kapur B, Klein J, Koren G. Heavily smoking women who cannot quit in pregnancy: evidence of pharmacokinetic predisposition. Ther. Drug Monit. 2001;23:189-91.

31. Dempsey D, Jacob P, III, Benowitz NL. Accelerated metabolism of nicotine and cotinine in pregnant smokers. J. Pharmacol. Exp. Ther. 2002;301: 594-8.

32. De Guia, N. Rethinking Stop-Smoking Medications: Myths and Facts. 1999. Ontario Medical Association.

33. Agency for Health Care Policy and Research. Clinical practice guideline: treating tobacco use and dependence. 2000. U.S. Department of Health and Human Services.

34. Royal College of Physicians (RCP). Nicotine Addiction in Britain. A report of the Tobacco Advisory Group of The Royal College of Physicians. 2000. London, RCP.

35. McNeill, A. and Hendrie, A. Regulation of nicotine replacement therapies: an expert consensus. pp 11-13, 34-37. 2001. Copenhagen, World Health Organization Regional Office for Europe.

36. Windsor RA. Smoking, Cessation and Pregnancy. In Samet JM, Yoon S-Y, eds. Women and the tobacco epidemic: Challenges for the 21 st century, pp 147-64. 2001. World Health Organization.

37. McNeill A, Foulds J, Bates C. Regulation of nicotine replacement therapies (NRT): a critique of current practice. Addiction 2001;96:1757-68.

38. Dempsey DA,.Benowitz NL. Risks and benefits of nicotine to aid smoking cessation in pregnancy. Drug Saf 2001;24:277-322.

39. Fagerstrom KO. Nicotine-Replacement Therapies. In Ferrence R, Slade J, Room R, Pope M, eds. Nicotine and Public Health, pp 199-208. Washington: American Public Health Association, 2000.

40. Chow WH, Daling JR, Weiss NS, Voigt L.F. Maternal cigarette smoking and tubal pregnancy. Ob- stet Gynecol 1988;71:167-70.

41. Handler A, Davis F, Ferre C, Yeko T. The relationship of smoking and ectopic pregnancy. Am J Public Health 1989;79:1239-42.

42. Coste J, Job-Spira N, Fernandez H. Increased risk of ectopic pregnancy with maternal cigarette smoking. Am J Public Health 1991;81:199-201.

43. Tuomivaara L,.Ronnberg L. Ectopic pregnancy and infertility following treatment of infertile couples: a follow-up of 929 cases. Eur.J Obstet Gynecol Reprod.Biol. 1991;42:33-8.

44. Phillips RS, Tuomala RE, Feldblum PJ, Schachter $\mathrm{J}$, Rosenberg MJ, Aronson MD. The effect of cigarette smoking, Chlamydia trachomatis infection, and vaginal douching on ectopic pregnancy. Obstet Gynecol 1992;79:85-90.

45. Saraiya M, Berg CJ, Kendrick JS, Strauss LT, Atrash HK, Ahn YW. Cigarette smoking as a risk factor for ectopic pregnancy. Am J Obstet Gynecol 1998; 178:493-8.

46. Castles A, Adams EK, Melvin CL, Kelsch C, Boulton ML. Effects of smoking during pregnancy. Five meta-analyses. Am J Prev Med 1999; 16:208-15.

47. Bouyer J, Coste J, Shojaei T, Pouly JL, Fernandez H, Gerbaud L et al. Risk Factors for Ectopic Pregnancy: A Comprehensive Analysis Based on a Large Case-Control, Population-based Study in France. Am J Epidemiol 2003;157:185-94.

48. Hadley CB, Main DM, Gabbe SG. Risk factors for preterm premature rupture of the fetal membranes. Am J Perinatol. 1990;7:374-9.

49. Harger JH, Hsing AW, Tuomala RE, Gibbs RS, Mead PB, Eschenbach DA et al. Risk factors for preterm premature rupture of fetal membranes: a multicenter case-control study. Am J Obstet Gynecol 1990;163:130-7.

50. Williams MA, Mittendorf R, Stubblefield PG, Lieberman E, Schoenbaum SC, Monson RR. Cigarettes, coffee, and preterm premature rupture of the membranes. Am J Epidemiol 1992;135:895903.

51. Ekwo EE, Gosselink CA, Woolson R, Moawad A. Risks for premature rupture of amniotic membranes. Int J Epidemiol 1993;22:495-503.

52. Spinillo A, Nicola S, Piazzi G, Ghazal K, Colonna L, Baltaro F. Epidemiological correlates of preterm premature rupture of membranes. Int $\mathrm{J}$ Gynaecol Obstet 1994;47:7-15.

53. Miller HC,.Jekel JF. Epidemiology of spontaneous premature rupture of membranes: factors in pre- 
term births. Yale J Biol Med 1989;62:241-51.

54. Karegard M,.Gennser G. Incidence and recurrence rate of abruptio placentae in Sweden. Obstet Gynecol 1986;67:523-8.

55. Ananth CV, Savitz DA, Luther ER. Maternal cigarette smoking as a risk factor for placental abruption, placenta previa, and uterine bleeding in pregnancy. Am J Epidemiol 1996;144:881-9.

56. Ananth CV, Smulian JC, Vintzileos AM. Incidence of placental abruption in relation to cigarette smoking and hypertensive disorders during pregnancy: a meta-analysis of observational studies. Obstet Gynecol 1999;93:622-8.

57. Cnattingius S, Mills JL, Yuen J, Eriksson O, Salonen $\mathrm{H}$. The paradoxical effect of smoking in preeclamptic pregnancies: smoking reduces the incidence but increases the rates of perinatal mortality, abruptio placentae, and intrauterine growth restriction. Am J Obstet Gynecol 1997;177:15661.

58. Saftlas AF, Olson DR, Atrash HK, Rochat R, Rowley D. National trends in the incidence of abruptio placentae, 1979-1987. Obstet Gynecol 1991;78:1081-6.

59. Spinillo A, Capuzzo E, Colonna L, Solerte L, Nicola S, Guaschino S. Factors associated with abruptio placentae in preterm deliveries. Acta Obstet Gynecol Scand. 1994;73:307-12.

60. Voigt LF, Hollenbach KA, Krohn MA, Daling JR, Hickok DE. The relationship of abruptio placentae with maternal smoking and small for gestational age infants. Obstet Gynecol 1990;75:771-4.

61. Raymond EG,.Mills JL. Placental abruption. Maternal risk factors and associated fetal conditions. Acta Obstet Gynecol Scand. 1993;72:633-9.

62. Williams MA, Lieberman E, Mittendorf R, Monson RR, Schoenbaum SC. Risk factors for abruptio placentae. Am J Epidemiol 1991;134:965-72.

63. Williams MA, Mittendorf R, Monson RR. Chronic hypertension, cigarette smoking, and abruptio placentae. Epidemiology 1991;2:450-3.

64. Himmelberger DU, Brown BW, Jr., cohen EN. Cigarette smoking during pregnancy and the occurrence of spontaneous abortion and congenital abnormality. Am J Epidemiol 1978;108:470-9.

65. Kline J, Stein ZA, Susser M, Warburton D. Smoking: a risk factor for spontaneous abortion. N. Engl. J Med 1977;297:793-6.

66. Dominguez-Rojas V, Juanes-Pardo JR, AstasioArbiza P, Ortega-Molina P, Gordillo-Florencio E. Spontaneous abortion in a hospital population: are tobacco and coffee intake risk factors? Eur.J Epidemiol 1994;10:665-8.

67. Armstrong BG, McDonald AD, Sloan M. Cigarette, alcohol, and coffee consumption and spontaneous abortion. Am J Public Health 1992;82:85-7.

68. Windham GC, Swan SH, Fenster L. Parental cigarette smoking and the risk of spontaneous abortion. Am J Epidemiol 1992;135:1394-403.

69. Ananth CV, Savitz DA, Luther ER. Maternal cigarette smoking as a risk factor for placental abruption, placenta previa, and uterine bleeding in pregnancy. Am J Epidemiol 1996;144:881-9.

70. Chelmow D, Andrew DE, Baker ER. Maternal cigarette smoking and placenta previa. Obstet Gynecol 1996;87:703-6.

71. Handler AS, Mason ED, Rosenberg DL, Davis FG. The relationship between exposure during pregnancy to cigarette smoking and cocaine use and placenta previa. Am J Obstet Gynecol 1994; 170:884-9.

72. Kramer MD, Taylor V, Hickok DE, Daling JR, Vaughan TL, Hollenbach KA. Maternal smoking and placenta previe. Epidemiology 1991;1991:3211.

73. Meyer MB, Jonas BS, Tonascia JA. Perinatal events associated with maternal smoking during pregnancy. Am J Epidemiol 1976;103:464-76.

74. Meyer MB,.Tonascia JA. Maternal smoking, pregnancy complications, and preinatal mortality. Am J Obstet Gynecol 1977;128:494-502.

75. Monica G, Lilja C. Placenta previa, maternal smoking and recurrence risk. Acta Obstet Gynecol Scand. 1995;74:341-5.

76. Naeye RL. Abruptio placentae and placenta previa: frequency, perinatal mortality, and cigarette smoking.

77. Williams MA, Mittendorf R, Lieberman E, Monson RR, Schoenbaum SC, Genest DR. Cigarette smoking during pregnancy in relation to placenta previa. Am J Obstet Gynecol 1991;165:28-32.

78. Zhang J,.Fried DB. Relationship of maternal smoking during pregnancy to placenta previa. Am J Prev Med 1992;8:278-82.

79. Mathai M, Skinner A, Lawton K, Weindling AM. Maternal smoking, urinary cotinine levels and birth-weight. Aust.N.Z.J Obstet Gynaecol 1990; 30:33-6.

80. Castro LC, Azen C, Hobel CJ, Platt LD. Maternal tobacco use and substance abuse: reported prevalence rates and associations with the delivery of small for gestational age neonates. Obstet Gynecol 
1993;81:396-401.

81. Cliver SP, Goldenberg RL, Cutter GR, Hoffman HJ, Davis RO, Nelson KG. The effect of cigarette smoking on neonatal anthropometric measurements. Obstet Gynecol 1995;85:625-30.

82. Conter V, Cortinovis I, Rogari P, Riva L. Weight growth in infants born to mothers who smoked during pregnancy. BMJ 1995;310:768-71.

83. Ahlsten G, Cnattingius S, Lindmark G. Cessation of smoking during pregnancy improves foetal growth and reduces infant morbidity in the neonatal period. A population-based prospective study. Acta Paediatr. 1993;82:177-81.

84. Aronson RA, Uttech S, Soref M. The effect of maternal cigarette smoking on low birth weight and preterm birth in Wisconsin, 1991 . Wis. Med J 1993;92:613-7.

85. Backe B. Maternal smoking and age. Effect on birthweight and risk for small-for-gestational age births. Acta Obstet Gynecol Scand. 1993;72:1726.

86. English PB, Eskenazi B, Christianson RE. Blackwhite differences in serum cotinine levels among pregnant women and subsequent effects on infant birthweight. Am J Public Health 1994;84:1439-43.

87. Eskenazi B, Prehn AW, Christianson RE. Passive and active maternal smoking as measured by serum cotinine: the effect on birthweight. Am J Public Health 1995;85:395-8.

88. Murphy NJ, Butler SW, Petersen KM, Heart V, Murphy CM. Tobacco erases 30 years of progress: preliminary analysis of the effect of tobacco smoking on Alaska Native birth weight. Alaska Med 1996;38:31-3.

89. Muscati SK, Gray-Donald K, Newson EE. Interaction of smoking and maternal weight status in influencing infant size. Can. J Public Health 1994; 85:407-12.

90. Zaren B, Lindmark G, Gebre-Medhin M. Maternal smoking and body composition of the newborn. Acta Paediatr. 1996;85:213-9.

91. Alameda County Low Birth Weight Study Group. cigarette smoking and the risk of low birth weight: a comparison in black and white women. Epidemiology 1990;1:201-5.

92. Bakketeig LS, Jacobsen G, Hoffman HJ, Lindmark G, Bergsjo P, Molne K et al. Pre-pregnancy risk factors of small-for-gestational age births among parous women in Scandinavia. Acta Obstet Gynecol Scand. 1993;72:273-9.

93. Bardy AH, Seppala T, Lillsunde P, Kataja JM,
Koskela P, Pikkarainen J et al. Objectively measured tobacco exposure during pregnancy: neonatal effects and relation to maternal smoking. Br.J Obstet Gynaecol 1993;100:721-6.

94. Bell R,.Lumley J. Alcohol consumption, cigarette smoking and fetal outcome in Victoria, 1985. Community Health Stud. 1989;13:484-91.

95. Brooke OG, Anderson HR, Bland JM, Peacock JL, Stewart CM. Effects on birth weight of smoking, alcohol, caffeine, socioeconomic factors, and psychosocial stress. BMJ 1989;298:795-801.

96. Cornelius MD, Taylor PM, Geva D, Day NL. Prenatal tobacco and marijuana use among adolescents: effects on offspring gestational age, growth, and morphology. Pediatrics 1995;95:738-43.

97. Ellard GA, Johnstone FD, Prescott RJ, Ji-Xian W, Jian-Hua M. Smoking during pregnancy: the dose dependence of birthweight deficits. Br.J Obstet Gynaecol 1996;103:806-13.

98. Nordentoft M, Lou HC, Hansen D, Nim J, Pryds $\mathrm{O}$, Rubin $\mathrm{P}$ et al. Intrauterine growth retardation and premature delivery: the influence of maternal smoking and psychosocial factors. Am J Public Health 1996;86:347-54.

99. Tenovuo AH, Kero PO, Korvenranta HJ, Erkkola RU , Klemi PJ, Tuominen J. Risk factors associated with severely small for gestational age neonates. Am J Perinatol. 1988;5:267-71.

100. Wen SW, Goldenberg RL, Cutter GR, Hoffman HJ, Cliver SP, Davis RO et al . Smoking, maternal age, fetal growth, and gestational age at delivery. Am J Obstet Gynecol 1990;162:53-8.

101. McDonald AD, Armstrong BG, Sloan M. Cigarette, alcohol, and coffee consumption and prematurity. Am J Public Health 1992;82:87-90.

102. Li CQ, Windsor RA, Perkins L, Goldenberg RL, Lowe JB. The impact on infant birth weight and gestational age of cotinine- validated smoking reduction during pregnancy. JAMA 1993;269:151924.

103. Ferraz EM, Gray RH, Cunha TM. Determinants of preterm delivery and intrauterine growth retardation in north-east Brazil. Int J Epidemiol 1990; 19:101-8.

104. Centers for Disease Control. Effects of maternal cigarette smoking on birth weight and preterm birth - Ohio, 1989. Morbidity and Mortality Weekly Report 1990;39:662-5.

105. Wilcox AJ. Birth weight and perinatal mortality: the effect of maternal smoking. Am J Epidemiol. 1993; 137:1098-104. 
106. Cnattingius S, Forman MR, Berendes HW, Graubard BI, Isotalo L. Effect of age, parity, and smoking on pregnancy outcome: a populationbased study. Am J Obstet Gynecol 1993;168: 16-21.

107. Heffner LJ, Sherman CB, Speizer FE, Weiss ST. Clinical and environmental predictors of preterm labor. Obstet Gynecol 1993;81:750-7.

108. Mainous AG, III,.Hueston WJ. The effects of smoking cessation during pregnancy on preterm delivery and low birthweight. J Fam Pract 1994; 38:262-6.

109. Meis PJ, Michielutte R, Peters TJ, Wells HB, Sands RE, Coles EC et al. Factors associated with term low birthweight in Cardiff, Wales. Paediatr.Perinat.Epidemiol 1997;11:287-97.

110. Olsen P, Laara E, Rantakallio P, Jarvelin MR, Sarpola A, Hartikainen AL. Epidemiology of preterm delivery in two birth cohorts with an interval of 20 years. Am J Epidemiol 1995;142:1184-93.

111. Shiono PH, Klebanoff MA, Rhoads GG. Smoking and drinking during pregnancy. Their effects on preterm birth. JAMA 1986;255:82-4.

112. Cnattingius S, Haglund B, Meirik O. Cigarette smoking as risk factor for late fetal and early neonatal death. BMJ 1988;297:258-61.

113. Malloy MH, Kleinman JC, Land GH, Schramm WF. The association of maternal smoking with age and cause of infant death. Am J Epidemiol 1988;128:46-55.
114. Raymond EG, Cnattingius S, Kiely JL. Effects of maternal age, parity, and smoking on the risk of stillbirth. Br.J Obstet Gynaecol 1994;101:301-6.

115. Schramm WF. Smoking during pregnancy: Missouri longitudinal study. Paediatr. Perinat. Epidemiol 1997;11 Suppl 1:73-83.

116. Cnattingius S, Forman MR, Berendes HW, Isotalo L . Delayed childbearing and risk of adverse perinatal outcome. A population-based study. JAMA 1992;268:886-90.

117. Walsh RA. Effects of maternal smoking on adverse pregnancy outcomes: examination of the criteria of causation. Hum Biol. 1994;66:1059-92.

118. Haglund B,.Cnattingius S. Cigarette smoking as a risk factor for sudden infant death syndrome. Am J Public Health 1990;80:29-32.

119. Kleinman JC, Pierre MB, Jr., Madans JH, Land GH, Schramm WF. The effects of maternal smoking on fetal and infant mortality. Am J Epidemiol 1988; 127:274-82.

120. Butler NR,.Goldstein H. Smoking in pregnancy and subsequent child development. Br. Med J 1973;4:573-5.

121. Sexton M, Hebel JR, Blackman J. Long-term consequences on cognition and physical growth associated with smoking and pregnancy. J SmokingRelated Dis. 1994;5:119-26.

122. Tong S, McMichael AJ. Maternal smoking and neuropsychological development in childhood: a review of the evidence. Dev Med Child Neurol. 1992;34:191-7. 